\title{
Cost-effectiveness comparison between non-penetrating deep sclerectomy and maximum-tolerated medical therapy for glaucoma within the Brazilian National Health System (SUS)
}

\author{
Comparação de custo-efetividade entre a esclerectomia profunda não penetrante e \\ a terapia clínica máxima tolerada para o glaucoma no Sistema Único de Saúde (SUS)
}

Ricardo Augusto Paletta Guedes ${ }^{1}$, Vanessa Maria Paletta Guedes ${ }^{1}$, Alfredo Chaoubah ${ }^{1}$

\begin{abstract}
Purpose: Non-penetrating deep sclerectomy (NPDS) has emerged as a viable option in the surgical management of open-angle glaucoma. Our aim is to assess the costeffectiveness of NPDS and to compare it to maximum medical treatment in a 5-year follow-up.

Methods: A decision analysis model was built. Surgical (NPDS) arm of the decision tree was observational (consecutive retrospective case series) and maximum medical treatment arm was hypothetical. Maximum medical therapy was considered a three-drug regimen (association of a fixed combination of timolol/dorzolamide [FCTD] and a prostaglandin analogue [bimatoprost, latanoprost or travoprost]). Cost-effectiveness ratio was defined as direct cost (US dollars) for each percentage of intraocular pressure (IOP) reduction. Horizon was 5 years and perspective is from the public health care service in Brazil (SUS). Incremental cost-effectiveness ratio (ICER) was calculated.

Results: Direct cost for each percentage of IOP reduction in 5 years (cost-effectiveness ratio) was US\$10.19 for NPDS; US\$37.45 for the association of a FCTD and bimatoprost; US\$ 39.33 for FCTD and travoprost; and US\$ 41.42 for FCTD and latanoprost. NPDS demonstrated a better cost-effectiveness ratio, compared to maximum medical therapy. The ICER was negative for all medical treatment options; therefore NPDS was dominant Conclusions: Despite some limitations, NPDS was both less costly and more effective than maximum medical therapy. From the Brazilian public health perspective, it was the most cost-effective treatment option when compared to maximum medical therapy (FCTD and prostaglandin).
\end{abstract}

Keywords: Glaucoma/economy; Filtering surgery/economy; Health care costs; Costeffectiveness evaluation

\section{RESUMO}

Objetivo: A esclerectomia profunda não penetrante (EPNP) é uma opção viável para o tratamento cirúrgico do glaucoma de ângulo aberto. O objetivo deste estudo é avaliar a relação custo-efetividade da EPNP e compará-la com terapia clínica máxima (TCM) em um acompanhamento de 5 anos.

Métodos: Um modelo de análise de decisão foi proposto comparando-seo tratamento cirúrgico (EPNP) versus a TCM. A avaliação da EPNP foi observacional retrospectiva de uma série consecutiva de casos e da TCM foi hipotética. A TCM foi considerada como o uso de três drogas (associação de uma combinação fixa de timolol/dorzolamida [CFTD] eum análogo de prostaglandina [bimatoprosta, latanoprosta ou travoprosta]). A relação custo-efetividade foi definida com o custo direto (em dólares) para cada porcentual de redução da pressão intraocular (PIO). A razão de custo-efetividade incremental (ICER) foi calculada. O seguimento foi de 5 anos e a perspectiva dos custos é do Sistema Único de Saúde (SUS).

Resultados: $O$ custo direto para cada porcentual de redução da PIO ao final de 5 anos (relação custo-efetividade) foi de US\$10,19 para a EPNP; US\$ 37,45 para a CFTD + bimatoprosta; US\$39,33 para CFTD + travoprosta; e US\$ 41,42 para CFTD + latanoprosta. A EPNP apresentou uma melhor relação custo-efetividade, quando comparada com a TCM. O índice ICER foi negativo, portanto a EPNP foi a opção terapêutica dominante.

Conclusão: AEPNP foi menos custosa e mais efetiva que a TCM. Do ponto devista do SUS, ela foi a opção mais custo-efetiva, quando comparada com a TCM.

Descritores: Glaucoma/economia; Cirurgia filtrante/economia; Custos de cuidados de saúde; Análise de custo-efetividade

\section{INTRODUCTION}

Growing costs in health care are an important issue to be considered in public health. Among health technology assessment different types of studies, cost-effectiveness and cost-utility analysis are useful tools to compare both costs and results (measured as effectiveness or as quality of life, respectively) for different interventions ${ }^{(1-3)}$. New treatment modalities need to be evaluated; in order to help decision makers to better allocate health resources ${ }^{(1)}$.

Economic impact of most prevalent eye diseases and their treatment is felt heavily on health services due especially to glaucoma, one of the leading causes of irreversible blindness in the world ${ }^{(4)}$. There is a trend of increasing costs in the future, as both incidence and prevalence of glaucoma are expected to be higher in the next years ${ }^{(5)}$.
Glaucoma direct costs have a major impact on health care, because it includes: chronic use of medications, surgical procedures, medical visits and frequent exams ${ }^{(6)}$. Glaucoma chargers are responsible for up to $12 \%$ of all medical expenses in glaucoma patients ${ }^{(7)}$. Medications contribute with a significant proportion of glaucoma related direct costs ${ }^{(6)}$. Rylander and Vold estimated the annual costs with a single medication in the United States. It varied from US\$150.81 to US\$ $873.98^{(8)}$. If a patient needs more than one medication, which is not unusuall(9,10), these costs are even higher.

The usual care in glaucoma is to initiate treatment with one medication (monotherapy) $)^{(11)}$. If the target intraocular pressure (IOP) is not reached, a second and, not rarely, a third medication are added ${ }^{(9-11)}$. Once the patient is already in a three-drug regimen (maximum me- 
dical therapy) and glaucoma is still progressing, it is usually the time for surgery ${ }^{(11)}$. However, many patients and, even their doctors, sometimes refuse to accept or indicate the surgical procedure due to some surgery-related potential risks. Therefore, many patients are kept under maximum medical therapy for a long period of time, leading to problems related to chronic use of medications, such as: ocular surface toxicity, costs, adherence, persistence and quality of life ${ }^{(12)}$.

Non-penetrating deep sclerectomy (NPDS) is a filtering glaucoma procedure, which is an alternative to trabeculectomy in patients with open-angle glaucoma ${ }^{(13,14)}$. Many studies proved its efficacy and safety and it has been recently introduced in the glaucoma surgical management in Brazil(14-17).

The aim of this study is to assess the cost-effectiveness of NPDS in a group of patients and to compare it to maximum medical therapy in a 5-year follow-up.

\section{METHODS}

A decision model was built in order to allow the comparison between the surgery group and the medication group (Figure 1).

The surgical arm of the decision analysis tree was observational and its data was derived from a retrospective chart review of consecutive cases submitted to NPDS in the same setting (Juiz de Fora - MG, Brazil), by the same surgical team, from 1999 to 2007. NPDS technique was described elsewhere ${ }^{(14)}$. Inclusion criteria were: diagnosis of primary open-angle glaucoma under maximum medical therapy and at least 5 years of follow-up after surgery. If both eyes of a patient were eligible, the authors chose the first operated eye for study. Exclusion criteria were: other types of glaucoma and cataract surgery in the 5-years of follow-up.

NPDS direct costs were based on the following variables:

- Price of NPDS paid by the Brazilian Public National Health System (SUS) using the code 04.05.05.032-1 (Glaucoma Filtering Surgery). Prices were obtained through the internet in the SIGTAP table ${ }^{(18)}$;

- Price and number of MMC units used intraoperatively;

- Price and number of medications used in the postoperative period. The authors estimated 1 bottle of $0.3 \%$ ciprofloxacin and 2 bottles of $0.1 \%$ dexamethasone per surgical intervention.
Another bottle of steroid was also included for goniopuncture or when 5-FU injections were needed;

- Price and number of 5-FU injections;

- Price and number of Nd:YAG laser goniopunctures;

- Price and number of surgical reinterventions;

- Price, number and type of glaucoma medications needed after surgery and for how long this medication was necessary for up to 5 years of follow-up.

Costs of transportation, medical visits, exams, as well as indirect costs (loss of productivity) were not included in the analysis.

Total NPDS direct cost (in 5 years) was divided by the total number of eyes to find the direct cost per eye. In order to allow the comparison with medications, which are used in both eyes of the same patient, we divided the total cost of medications by two. So we could compare the costs per treated eye and not per patient.

Effectiveness was defined as the mean percentage of intraocular pressure (IOP) reduction from the preoperative period to the end of follow-up and was calculated as follows: [(mean baseline IOP - mean final IOP)/mean baseline IOP] x 100 .

In order to evaluate the NPDS ability to control IOP and allow comparisons to literature, we also calculated different NPDS success rates: IOP $<21 \mathrm{mmHg}$ without medication; IOP $<18 \mathrm{mmHg}$ without medication and IOP $<18 \mathrm{mmHg}$ with or without medication. Any intra and postoperative difficulties or complications were registered.

Although the patients included in this study were under maximum medical therapy (fixed combination of timolol/dorzolamide and a prostaglandin), their 5-year cost estimation was hypothetical. We assumed the hypothesis that those patients were kept under medication for the whole follow-up period (5 years) and projected the costs and effectiveness. The medications used as maximum medical therapy in this study were: fixed combination of timolol/dorzolamide (FCTD) associated with a prostaglandin analogue (bimatoprost or latanoprost or travoprost).

We used the average wholesale price (AWP) for the medications costs and their effectiveness was based on the literature. For the prostaglandin analogues effectiveness (mean percentage of IOP reduction), we chose to use Aptel et al. study ${ }^{(19)}$. They performed a meta-analysis of randomized controlled trials involving prostaglandin analogues. We decided to use peak values (higher percentage

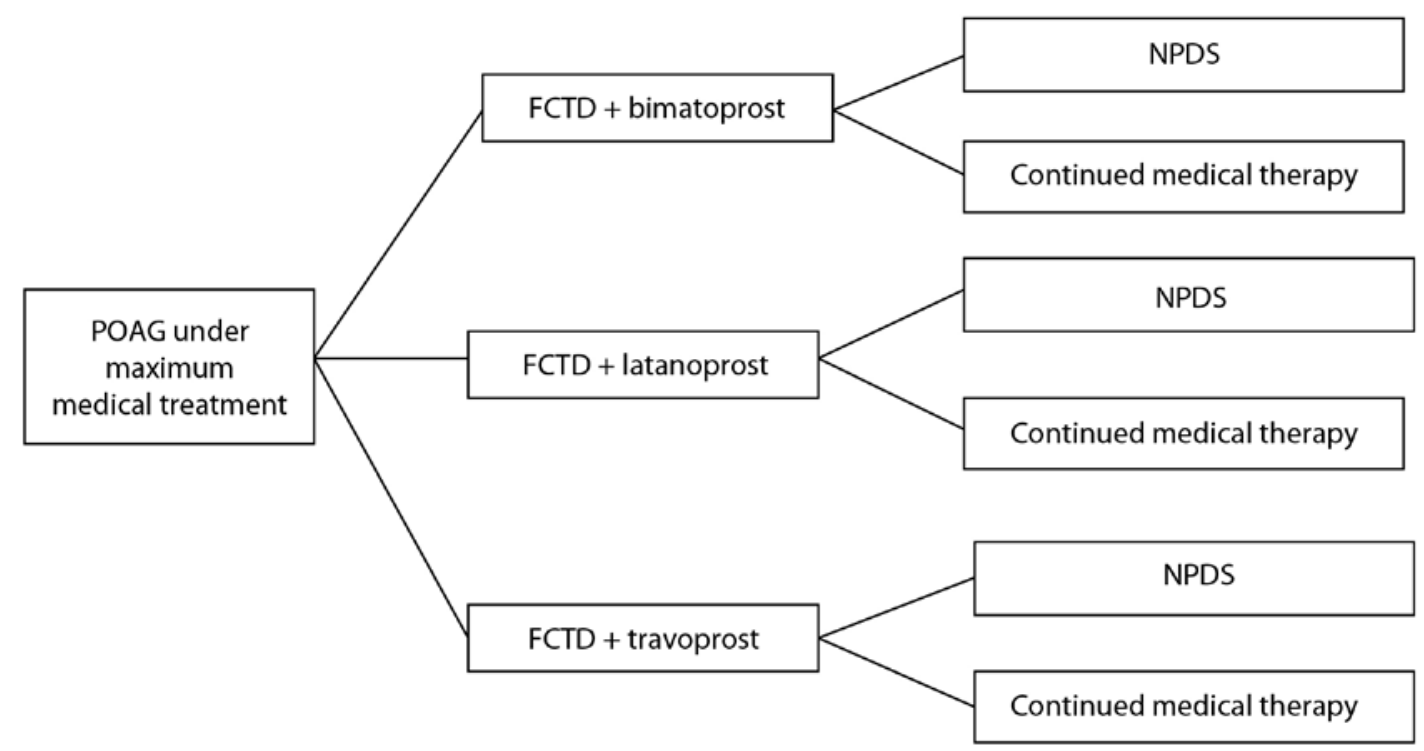

$\mathrm{POAG}=$ primary open-angle glaucoma; $\mathrm{FCTD}=$ fixed combination of $0.5 \%$ timolol maleate $/ 2 \%$ dorzolamide; NPDS= non penetrating deep sclerectomy

Figure 1. Decision analysis tree comparing surgery (observational arm) versus maximum medical therapy group (hypothetical arm). 
of IOP reduction) for effectiveness. For the additive effect of FCTD over the prostaglandin analogue, only two studies were found in the literature and all of them evaluated the IOP reduction effect of FCTD added to latanoprost $t^{(20,21)}$. We assumed the same effect for the other two prostaglandin analogues (bimatoprost and travoprost). Between those two studies, we chose to use Hatanaka et al. study (21), because of the more appropriate methodology and because it was made in a Brazilian population.

All prices were obtained in January 2010 in "reais" (Brazil's currency). The authors converted the "reais" values into US dollar values using January $22^{\text {nd }} 2010$ as reference ( 1 dollar $=1.82$ "reais").

Cost-effectiveness of each decision tree arm was calculated through the division of direct cost/eye by the mean percentage of IOP reduction and was defined as the cost for each percentage of IOP reduction over 5 years.

We calculated the incremental cost, incremental effectiveness and the incremental cost-effectiveness ratio (ICER).

We used a 3\% discount rate.

Univariate sensitivity analysis was performed using IOP reduction trough (lower percentage of IOP reduction) values as prostaglandin analogues effectiveness and different discount rates (0\%; 5\% and 10\%).

All statistical analysis were performed using SPSS 13 (SPSS Inc., Chicago, Illinois) and Microsoft Excel (Microsoft Inc., 2007).

The Ethics Committee of the Federal University of Juiz de Fora approved this study.

\section{RESULTS}

Two-hundred twenty-eight eyes met the inclusion criteria, but 57 were excluded due to missing data in their charts. One hundred seventy-one eyes were evaluated in the observational arm of the decision analysis tree. Table 1 shows the demographics of the studied population. NPDS direct costs and resources used are demonstrated in table 2.

In the NPDS arm, mean preoperative IOP was $24.28 \mathrm{mmHg}$ and mean final IOP was $12.95 \mathrm{mmHg}(\mathrm{p}<0.001$; Paired Student T Test). Mean percentage of IOP reduction was $46.66 \%$ from baseline to the end of follow-up. Success rates were: $70.76 \%(I O P<21 \mathrm{mmHg}$ without medication); $68.42 \%$ (IOP $<18 \mathrm{mmHg}$ without medication); and $90.64 \%$ (IOP $<18 \mathrm{mmHg}$ with or without medication). Intraoperative complications were few: conversion to trabeculectomy (4.7\%) and microperforations (14\%). Postoperative complication rates were also low: hyphema (0.06\%); choroidal detachment (0.06\%); shallow anterior chamber (1.8\%); bleb leaks (3.5\%); bleb fibrosis (19.3\%).

In the maximum medical therapy arm, costs are displayed in table 3 and mean percentage of IOP reduction varied from $26.98 \%$ (8PM) to $33.08 \%$ (8AM) for bimatoprost; from $24.49 \%$ (8PM) to $33.46 \%$ (8AM) for latanoprost and from $26.52 \%$ (4PM) to $30.98 \%$ (8AM) for travoprost. Peak values used for cost-effectiveness analysis were those from $8 \mathrm{AM}$ and trough values used for sensitivity analysis were those from 8PM for bimatoprost and latanoprost and 4PM for travoprost. Additive effect of FCTD found in the literature was $8.7 \%$.

Cost-effectiveness results, incremental cost and incremental effectiveness are displayed in table 4. NPDS was both less costly and more effective than maximum medical therapy; therefore it was dominant.

Sensitivity analysis using trough values for IOP reduction effect did not show any differences and NPDS still remained dominant over the other treatment options. Results were not interfered by different discount rates (0\%; $5 \%$ and $10 \%)$.

\section{DISCUSSION}

Our results show that NPDS demonstrated a better cost-effectiveness ratio, compared to maximum medical therapy and it was dominant over all the studied treatment options. NPDS presented the lowest direct cost for each percentage of IOP reduction in 5 years (cost-effectiveness ratio).

Taking into consideration the assumptions of our study and from the Brazilian public health care provider perspective, surgery (NPDS) is the most cost-effective treatment option in patients under maximum medical therapy for glaucoma over a 5 -year period. These results should not be different for another surgical option, trabeculectomy, as literature has shown similar long-term results for both techniques ${ }^{(13-17)}$. The main differences between these two techniques are early postoperative comfort and number of complications. Trabeculectomy patients face more complications in that period than NPDS patients ${ }^{(13-17)}$. Costs for both techniques should not be very different, but it is a matter for further investigation.

We chose to use the mean percentage of IOP reduction as our effectiveness outcome measure, in order to make comparisons with medications easier. NPDS had the highest percentage of IOP reduction over 5 years (46.66\%) and medications varied from $39.68 \%$ (FCTD and travoprost) to $42.16 \%$ (FCTD and latanoprost). Differences among medical therapies effectiveness values are not clinically significant. NPDS effectiveness is in agreement with the literature for any glaucoma filtering procedure (both NPDS and trabeculectomy). Results in the literature show an IOP reduction between 44\% and $47 \%$ for NPDS ${ }^{(13-17)}$. Lichter et al. found values between $45 \%$ and $48 \%$ in the CIGTS (Collaborative Initial Glaucoma Treatment Study) for the trabeculectomy group ${ }^{(10)}$

Despite very similar effectiveness results for the three medical therapies (39.68\%; $41.78 \%$ and $42.16 \%$ ), in our cost-effectiveness analysis, some differences appear among them, mainly because their costs are not the same. Our results show that the most effective medical treatment (FCTD + latanoprost) is not the most cost-effective.
Table 1. Demographics of the population submitted to non-penetrating deep sclerectomy surgery (observational group)

\begin{tabular}{lcc}
\hline \multicolumn{2}{c}{ Population characteristics $(\mathbf{n = 1 7 1 )}$} \\
\hline Age (years) mean \pm standard deviation & $64.87 \pm 13.65$ \\
Race Caucasian & $73.68 \%$ \\
& Non-caucasian & $26.32 \%$ \\
$\quad$ (blacks; mixed blacks-whites) & $24.28 \pm 5.21$ \\
Pre-IOP (mmHg) mean \pm standard deviation & & $0.75 \pm 0.14$ \\
C/D & & $15.2 \%$ \\
Visual field stage & Early & $26.9 \%$ \\
(Hodapp, Parrish and Anderson classification) $^{(22)}$ & Moderate & $57.9 \%$ \\
\hline
\end{tabular}

$\mathrm{IOP}=$ intraocular pressure; $\mathrm{C} / \mathrm{D}=$ cup to disc vertical ratio
Table 2. NPDS cost composition in a 5-year follow-up

\begin{tabular}{lcccc}
\hline NPDS cost composition & Unit Cost(US\$) & Units & Total Cost (US\$) \\
\hline NPDS & 282.06 & 171 & $48,232.26$ \\
Resources used & Mitomycin C & 32.42 & 159 & $5,154.78$ \\
& 5-Fluoro-uracyl & 15.39 & 51 & 784.89 \\
& Goniopuncture & 24.73 & 37 & 915.01 \\
& New surgery & 282.06 & 42 & $11,846.52$ \\
& Medications* & NA & NA & $27,292.60$ \\
Total cost A & NA & NA & $94,226.06$ \\
Total costpereye (=Total costA $\div 171)$ & NA & NA & 551.03 \\
\hline
\end{tabular}

NPDS= non-penetrating deep sclerectomy

* = medications costs included all necessary antibiotics, steroids and any hypotensive medication needed in the postoperative period up to 5 years of follow-up 
Table 3. Medical therapy groups costs

\begin{tabular}{lccccc}
\hline Treatment & AWP(US\$) & Daily cost per eye (US\$) & Monthly cost per eye (US\$) & Yearly cost per eye (US\$) & 5-Year cost per eye (US\$) \\
\hline FCTD + bimatoprost & 96.96 & 1.01 & 30.23 & 362.76 & $1,813.78$ \\
FCTD + latanoprost & 108.43 & 1.13 & 33.74 & 404.86 & $2,024.30$ \\
FCTD + travoprost & 93.20 & 1.00 & 30.16 & 361.86 & $1,809.28$ \\
\hline
\end{tabular}

$\mathrm{FCTD}=$ fixed combination of $0.5 \%$ timolol and $2 \%$ dorzolamide; $\mathrm{AWP}=$ average wholesale price

Table 4. Cost-effectiveness, incremental cost, incremental effectiveness and incremental cost-effectiveness ratio (ICER) of treatment options

\begin{tabular}{|c|c|c|c|c|c|c|}
\hline \multicolumn{7}{|c|}{ Cost-effectiveness analysis } \\
\hline Treatment options & $\begin{array}{l}\text { 5-year cost* } \\
\text { (US\$) }\end{array}$ & $\begin{array}{c}\text { Effectiveness } \\
\text { (\%) }\end{array}$ & $\begin{array}{l}\text { Cost-effectiveness } \\
\text { ratio (US\$/\%) }\end{array}$ & $\begin{array}{l}\text { Incremental } \\
\text { cost (US\$) }\end{array}$ & $\begin{array}{c}\text { Incremental } \\
\text { effectiveness (\%) }\end{array}$ & ICER (US\$/\%) \\
\hline NPDS & 475.32 & 46.66 & 10.19 & & & \\
\hline FCTD + travoprost & $1,560.70$ & 39.68 & 39.33 & $1,085.38$ & -6.98 & Dominated \\
\hline FCTD + bimatoprost & $1,564.58$ & 41.78 & 37.45 & $1,089.26$ & -4.88 & Dominated \\
\hline FCTD + latanoprost & $1,746.18$ & 42.16 & 41.42 & $1,270.86$ & -4.50 & Dominated \\
\hline
\end{tabular}

Actually, our data demonstrated that it had the worst cost-effectiveness ratio. It can be explained by the highest cost of this treatment option compared to the others. Recently, we have observed a trend in lowering the costs of all prostaglandins analogues, as generic formulations become available. This can cause an impact on our results and needs to have further investigation.

Efficacy of NPDS is already proven in the literature. Two metaanalysis investigations found similar success rates. To achieve an IOP $<21 \mathrm{mmHg}$ without medication, Cheng et al. found 67.8\% (95\% confidence interval [Cl]: 61.4\%-74.3\%) of success ${ }^{(15)}$. Hondur et al. found a success rate of $67.1 \%$ for NPDS with antimetabolite ${ }^{(16)}$. Our study showed a success rate (IOP $<21 \mathrm{mmHg}$ without medication) slightly above those found in the literature (70.76\%), but within the limits for the $95 \% \mathrm{Cl}$ found by Cheng et al. ${ }^{(15)}$.

The majority of our cases (84.8\%) had moderate to advanced visual field loss. According to the Advanced Glaucoma Intervention Study $(\mathrm{AGIS})^{(23)}$, these kinds of patients need target pressures below $18 \mathrm{mmHg}$ in all measures, with a mean IOP close to $12.3 \mathrm{mmHg}$ to avoid progression. At the end of follow-up (5 years), IOP $<18 \mathrm{mmHg}$ without any medication, and with-or-without medication was achieved in $68.42 \%$ and $90.64 \%$ of studied eyes, respectively. The mean IOP after 5 years of surgery was $12.95 \mathrm{mmHg}$, reaffirming NPDS' ability to achieve target IOP in the great majority of eyes.

Intra and postoperative complications rates were similar to other published studies ${ }^{(13-17)}$. The most frequent complication was filtering bleb fibrosis (19.3\%). This explains the number of 5-FU injections (51 injections) and reoperations (42/171). All eyes submitted to a second NPDS were well controlled up to 5 years of follow-up.

The authors did not take into consideration persistence and adherence to medical therapy, as medications evaluations were hypothetical. These can influence our results, as the duration of the bottle can vary according to those parameters.

Another limitation is that medication prices were based on the average wholesale price. Health care providers usually buy a large quantity of bottles, thereby receiving discounts and minimizing costs. Accordingly, an individual can benefit from pharmacy discounts.

NPDS direct cost calculation excluded medical visits and exams. This can limit our findings, as an operated patient tends to need more visits than a patient under medical therapy. From the health care provider (payer) perspective, this influence is minimized as most of postoperative visits occur within the first month, when costs are still included in the surgical procedure charges. An increase in indirect costs (absence from work) is expected to happen and needs to be investigated. The eyes submitted to NPDS were in different glaucoma stages, which can influence the amount of resources used (5-FU needling, medications, etc) and, therefore, their costs in the postoperative period. We speculate that more advanced glaucomas tend to need more resources and generate more costs than early ones. However, we chose to use all glaucoma stages in order to simulate the "real world" where indication of surgery can occur in both early and advanced glaucomas.

We also excluded from our analysis the need for cataract surgery in both arms (surgical and medical therapy). Cataract formation or progression is an important issue to consider after trabeculectomy, but not after NPDS. The majority of authors believe that NPDS does not interfere with cataract formation or progression ${ }^{(13)}$. We chose not to include cataract surgery on our analysis to keep our model as simple as possible and to avoid any influence of the cataract surgery on patient's IOP.

The most cost-effective medication is not always the best therapy. The most cost-effective prostaglandin analogue in every study was bimatoprost, which is known however to have poor persisten$\mathrm{ce}^{(24-27)}$. Surgical complications can also have a negative impact on patient's perceived quality of life. Incorporating quality of life as an effectiveness outcome measure would be useful and a cost-utility analysis on that matter would be interesting. Therefore, it is important to consider our results in a societal and collective perspective and applicable only for patients covered by the Brazilian public health service (SUS). Supplementary or private health services practice other prices and in these realities, our results could be entirely different. Adaptations must be done on an individual basis.

In our study, taking into consideration all assumptions and limitations, NPDS was both less costly and more effective than maximum medical therapy. From the Brazilian public health service (SUS) perspective, NPDS was the most cost-effective treatment option when compared to maximum medical therapy (FCTD and prostaglandin) over a 5-year period. 


\section{REFERENCES}

1. Banta HD, Luce BR. Health care technology and it is assessment: an international perspective. Oxford: Oxford University Press; 1993.

2. Doshi A, Singh K. Cost-effective evaluation of the glaucoma suspect. Curr Opin Ophthalmol. 2007;18(2):97-103

3. Frick KD, Kymes SM. The calculation and use of economic burden data. Br J Ophthalmol. 2006;90(3):255-7.

4. Resnikoff S, Pascolini D, Etya'ale D, Kocur I, Pararajasegaram R, Pokharel GP, Mariott SP. Global data on visual impairment in the year 2002. Bull World Health Organ. 2004; 82(11):844-51.

5. Quigley HA, Broman AT. The number of people with glaucoma worldwide in 2010 and 2020. Br J Ophthalmol. 2006;90(3):262-7. Comment in Br J Ophthalmol. 2006; 90(3):253-4.

6. Traverso CE, Walt JG, Kelly SP, Hommer AH, Bron AM, Denis P, et al. Direct costs of glaucoma and severity of the disease: a multinational long term study of resource utilisation in Europe. Br J Ophthalmol. 2005;89(10):1245-9.

7. Lee PP, Levin LA, Walt JG, Chiang T, Katz LM, Dolgitser M, et al. Cost of patients with primary open-angle glaucoma: a retrospective study of commercial insurance claims data. Ophthalmology. 2007;114(7):1241-7.

8. Rylander NR, Vold SD. Cost analysis of glaucoma medications. Am J Ophthalmol. 2008;145(1):106-13. Comment in Am J Ophthalmol. 2008;145(6):1108-9; author reply 1109.

9. Kass MA, Heuer DK, Higginbotham EJ, Johnson CA, Keltner JL, Miller JP, et al. The Ocular Hypertension Treatment Study: a randomized trial determines that topical ocular hypotensive medication delays or prevents the onset of primary open-angle glaucoma. Arch Ophthalmol. 2002;120(6):701-13; discussion 829-30.

10. Lichter PR, Musch DC, Gillespie BW, Guire KE, Janz NK, Wren PA, Mills RP; CIGTS Study Group. Interim clinical outcomes in the Collaborative Initial Glaucoma Treatment Study comparing initial treatment randomized to medications or surgery. Ophthalmology. 2001;108(11):1943-53. Comment in Ophthalmology. 2003;110(2):249; author reply 249. Ophthalmology. 2001;108(1 1):1939-40. Ophthalmology. 2003;110(2):250-1. Ophthalmology. 2003;110(2):249; author reply 249-50.

11. European Glaucoma Society. Terminology and guidelines for glaucoma. $2^{\text {nd }}$ ed. Savona, Italy: Dogma; 2003

12. Schwartz GF, Quigley HA. Adherence and persistence with glaucoma therapy. Surv Opththalmol. 2008;53(Suppl 1):S57-68.

13. Mendrinos E, Mermoud A, Shaarawy T. Nonpenetrating glaucoma surgery. Surv Ophthalmol. 2008;53(6):592-630.
14. Guedes RAP, Guedes VMP. Cirurgia filtrante não penetrante: conceito, técnicas e resultados. Arq Bras Oftalmol. 2006;69(4):605-13.

15. Cheng JW, Ma XY, Wei RL. Efficacy of non-penetrating trabecular surgery for open angle glaucoma: a meta-analysis. Chin Med J (Engl). 2004;117(7):1006-10.

16. Hondur A, Onol M, Hasanreisoglu B. Nonpenetrating glaucoma surgery: meta-analysis of recent results. J Glaucoma. 2008;17(2):139-46.

17. Bissig A, Rivier D, Zaninetti M, Shaarawy T, Mermoud A, Roy S. Ten years follow-up after deep sclerectomy with collagen implant. J Glaucoma. 2008;17(8):680-6.

18. Brasil. Ministério da Saúde. Sistema de Gerenciamento da Tabela de Procedimentos, Medicamentos e OPM do SUS - SIGTAP [Internet]. [citado 2010 Jan 30]. Disponível em: http://sigtap.datasus.gov.br/tabela-unificada/app/sec/inicio.jsp.

19. Aptel F, Cucherat M, Denis P. Efficacy and tolerability of prostaglandin analogs: a meta-analysis of randomized controlled trials. J Glaucoma. 2008;17(8):667-73. Comment in J Glaucoma. 2009;18(6):498; author reply 498-9.

20. Lesk MR, Koulis T, Sampalis F, Sampalis JS, Bastien NR. Effectiveness and safety of dorzolamide-timolol alone or combined with latanoprost in open-angle glaucoma or ocular hypertension. Ann Pharmacother. 2008:42(4):498-504.

21. Hatanaka M, Reis A, Sano ME, Susanna R Jr. Additive intraocular reduction effect of fixed combination of maleate timolol $0.5 \%$ /dorzolamide $2 \%$ (Cosopt) on monotherapy with latanoprost (Xalatan) in patients with elevated intraocular pressure: a prospective, 4-week, open-label, randomized, controlled clinical trial. J Glaucoma. 2010;19(5):331-5.

22. Hodapp E, Parrish RK, Anderson DR. Clinical decisions in glaucoma. St. Louis: Mosby; 1993. p.52-61.

23. The Advanced Glaucoma Intervention Study (AGIS): 7. The relationship between control of intraocular pressure and visual field deterioration. The AGIS Investigators. Am J Ophthalmol. 2000;130(4):429-40. Comment in Am J Ophthalmol. 2000;130(4):490-1.

24. Guedes RAP, Guedes VMP, Chaoubah A. Custo-efetividade dos análogos de prostaglandinas no Brasil. Rev Bras Oftalmol. 2008;67(6):281-6.

25. Frenkel RE, Frenkel M, Toler A. Pharmacoeconomic analysis of prostaglandin and prostamide therapy for patients with glaucoma or ocular hypertension. BMC Ophthalmol. 2007;7:16.

26. Noecker RJ, Walt JG. Cost-effectiveness of monotherapy treatment of glaucoma and ocular hypertension with the lipid class of medications. Am J Ophthalmol. 2006; 141(1 Suppl):S15-21.

27. Reardon G, Schwartz GF, Mozaffari E. Patient persistency with topical ocular hypotensive therapy in a managed care population. Am J Ophthalmol. 2004;137(1 Suppl): S3-12. 